\title{
DESEMPENHO FOTOSSINTÉTICO DE FOLHAS JOVENS E MADURAS DE Vochysia cinnamomea (Vochysiaceae) EM ÁREAS DE CERRADO RUPESTRE INTACTAS E PÓS-QUEIMADA
}

\author{
PHOTOSYNTHETIC PERFORMANCE OF YOUNG AND MATURE LEAVES OF \\ Vochysia cinnamomea (Vochysiaceae) AT INTACT AND AFTER FIRE AREAS OF \\ CERRADO RUPESTRE
}

\section{Sandro Mayrink PAULA ${ }^{1}$; Emmanuel Rezende NAVES ${ }^{1}$; Izabela Moreira FRANCO'; Kim Junqueira Manna PADUA'; Kleber Resende SILVA ${ }^{1}$; Wesley Peixoto FERNANDES; Denis Coelho de OLIVEIRA²; José Pires de LEMOS-FILHO; Ana Sílvia Franco Pinheiro MOREIRA ${ }^{2}$}

1. Aluno de mestrado do Programa de Pós-Graduação em Biologia Vegetal, Instituto de Biologia - IB, Universidade Federal de Uberlândia - UFU, Uberlândia, MG, Brasil; 2. Professor(a), Doutor(a), IB - UFU, Uberlândia, MG, Brasil. anasilviamoreira@gmail.com;3. Professor, Doutor, Departamento de Botânica; Instituto de Ciências Biológicas; Universidade Federal de Minas Gerais, Belo Horizonte, MG, Brasil.

\begin{abstract}
RESUMO: O fogo exerce um papel importante como modelador dos ecossistemas de diversas formações vegetais, especialmente o Cerrado. Sua ação induz a brotação em diversas espécies, muitas vezes formando folhas mais vigorosas e fisiologicamente mais ativas. Nesse contexto, o presente trabalho investigou o desempenho fotossintético de folhas jovens e maduras de Vochysia cinnamomea Pohl (Vochysiaceae) em resposta à ação do fogo natural sobre uma área de cerrado rupestre da Serra da Canastra, Minas Gerais, comparando-se; (1) folhas jovens de área queimada e não queimada e (2) folhas jovens e maduras de um mesmo indivíduo. Foram analisadas folhas maduras de indivíduos de área não queimada cuja brotação ocorreu anterior à queimada, e folhas jovens de indivíduos de áreas queimadas e não queimadas cuja brotação ocorreu após a passagem do fogo. Foram coletados e analisados dados relativos às taxas fotossintéticas, rendimento quântico potencial e efetivo, taxa relativa de transporte de elétrons, assimilação líquida de $\mathrm{CO}_{2}$, condutância estomática, transpiração e teores de clorofila. Não houve diferenças significativas entre as folhas jovens da área queimada e da área não queimada em relação aos processos fisiológicos testados. Desta forma não há nenhum tipo de resposta rápida em relação à passagem do fogo. Entretanto, foram encontradas diferenças significativas quando comparadas folhas jovens e maduras. É fato que folhas jovens de $V$. cinnamomea são estruturalmente distintas de folhas maduras, são mais suculentas e pilosas enquanto as folhas maduras são mais coriáceas, glabras e com cutícula evidente. Estas diferenças estruturais e os estágios fisiológicos de maturação distintos se refletem nas características fisiológicas estudadas nestas folhas que, quando maduras apresentam-se com menor grau de fotoinibição, maior teor de clorofilas e maior assimilação líquida de $\mathrm{CO}_{2}$.
\end{abstract}

PALAVRAS-CHAVE: Clorofila. Fotoinibição. Rendimento quântico. Taxa relativa de transporte de elétrons. Trocas gasosas.

\section{INTRODUÇÃO}

Um dos aspectos mais característicos do Cerrado é a ocorrência de queimadas que modela as fitofisionomias e a história evolutiva da vegetação (GOTTSBERGER; SILBERBAUERGOTTSBERGER, 2006). Estratégias como resistência, sobrevivência ou regeneração foram relatadas como resultado de adaptações morfofisiológicas ao estresse gerado pela ação do fogo (COUTINHO, 1977). A regeneração possibilita a formação de ramos secundários, como ocorre em Vochysia divergens Pohl, espécie típica do Cerrado e sujeita às queimadas (ARIEIRA; CUNHA, 2006). É fato que a passagem do fogo induz a brotação em diversas espécies e, a depender da frequência, as novas folhas tornam-se vigorosas e com alto potencial de crescimento (FURLEY, 2002). Em muitos casos após exposição a este agente, as plantas apresentam maiores taxas fotossintéticas, condutância estomática e concentração de nitrogênio nas folhas, além de um melhor aproveitamento da água nos períodos de seca devido a um menor potencial osmótico (KNAPP, 1985).

Após a brotação, durante o processo de expansão foliar, a folha sofre mudanças estruturais que levam ao amadurecimento do ponto de vista fisiológico e tecidual. Em estudos com arbóreas tropicais, Krause et al. (1995) demonstraram que folhas jovens, quando comparadas com as folhas maduras, podem conter até metade do teor de pigmentos cloroplastídicos por unidade de área e menor capacidade fotossintética. De acordo com 
estes autores, apesar do maior investimento em pigmentos fotoprotetores, as folhas jovens apresentam maior susceptibilidade a danos no fotossistema II (PSII), detectados pelo processo de fotoinibição. Estudos que busquem avaliar o desempenho fotossintético em folhas jovens e maduras de Vochysia cinnamomea são inéditos, principalmente quando o efeito do fogo é testado.

No Brasil, ocorrem seis gêneros da família Vochysiaceae e cerca de 160 espécies, sendo Vochysia o gênero mais numeroso e com muitas espécies endêmicas (FRANÇA, 2015a). Dessas, $V$. cinnamomea Pohl é frequente nos biomas Cerrado e Mata Atlântica, com distribuição restrita aos estados do Mato Grosso, Goiás, São Paulo e Minas Gerais (FRANÇA, 2015b). Considerando a susceptibilidade dessa espécie às queimadas frequentes no Cerrado e às alterações fisiológicas decorrentes da ação do fogo e do estado de maturação das folhas, o presente estudo teve como objetivo investigar alterações fisiológicas em folhas de indivíduos de $V$. cinnamomea acometidos pelo fogo, visando responder as seguintes questões: (i) folhas jovens decorrentes de brotação após o fogo apresentam distinção nas taxas de fotossíntese quando comparadas com folhas de mesma idade das áreas não queimadas? (ii) Uma vez que nas áreas não queimadas as folhas maduras permanecem intactas nesta espécie, as folhas em diferentes estágios de desenvolvimento apresentam o mesmo desempenho fotossintético? $V$. cinnamomea ocorre em grande frequência na região, permitindo que folhas jovens decorrentes da brotação em áreas queimadas e não queimadas fossem comparadas quanto ao seu desempenho fotossintético e quanto ao seu teor de clorofilas. Folhas maduras remanescentes da brotação anterior e conservadas na área não queimada foram analisadas como base comparativa para interpretação dos resultados obtidos com as folhas jovens.

\section{MATERIAL E MÉTODOS}

O estudo foi conduzido em uma área de cerrado rupestre da Serra da Canastra, município de Delfinópolis, Minas Gerais. A área é sujeita a frequentes queimadas (MEDEIROS; FIEDLER, 2004), sendo que a coleta de dados foi realizada em outubro de 2012, período de transição entre a estação seca (junho a outubro) e a chuvosa (dezembro a fevereiro), das 06:00 às 18:00, durante a primeira brotação após incidência de fogo natural. Estudos mostram que a Serra da Canastra apresenta queimadas periódicas (média de 19.789,17 ha foram queimados anualmente entre 1988 e 2008), cujas origens podem ser naturais (por raio) ou ocasionadas pelo homem (incendiários ou limpeza para pastagem), e se concentram na estação seca (MAGALHÃES et al., 2012). A localidade apresenta clima subtropical úmido do tipo Cwa (KOTTEK et al., 2006). A temperatura e umidade foram monitoradas utilizando-se um termohigrômetro (Instrutherm HT-270, Itest Medição e Automação Ltda., Brasil) e a radiação fotossinteticamente ativa (PAR) foi monitorada com auxílio de um sensor quântico (LI 190, Li-cor, USA).

Vochysia cinnamomea apresenta folhas simples, inteiras, localizadas nos ápices dos ramos e verticiladas. Quando maduras, as folhas apresentam coloração verde intenso, são mais coriáceas, glabras e com cutícula evidente. As folhas jovens são estruturalmente distintas das folhas maduras, sendo mais suculentas e pilosas, com coloração verde desbotada. Foram selecionados 12 indivíduos adultos de $V$. cinnamomea com portes similares, e localizados próximos entre si para viabilizar o monitoramento das variáveis fisiológicas ao longo do dia. Desses, seis estavam localizados em área exposta ao fogo, e os demais não haviam sido expostos a esta condição. Os indivíduos da área não queimada apresentavam folhas jovens e maduras (Figura1A), enquanto que os indivíduos da área queimada apresentavam apenas folhas jovens, provenientes da brotação pós-fogo de 2012 (Figura1B).

Folhas jovens pertencentes ao segundo verticilo foram utilizadas para as amostragens, sendo distintas das folhas maduras pela coloração, grau de pilosidade e textura. Para as folhas maduras, procuraram-se as folhas intactas, minimizando o impacto por herbivoria. Todas as análises foram realizadas no campo, de forma que as plantas permaneceram intactas.

$\mathrm{O}$ teor de clorofila foi medido com um clorofilômetro (SPAD-502, Konica Minolta, Japão) ao longo do dia (das 8:00 às 18:00, de duas em duas horas), utilizando-se uma amostragem de quatro folhas de seis indivíduos para cada condição $(n=24)$.

Os valores de rendimento quântico potencial $(\mathrm{Fv} / \mathrm{Fm})$, rendimento quântico efetivo $(\Delta \mathrm{F} / \mathrm{Fm}$ ') e taxa relativa de transporte de elétrons (ETR) foram determinados ao longo do dia (duas em duas horas) em folhas jovens e maduras de quatro indivíduos de cada área, utilizando-se um medidor de fluorescência modulada (Mini-PAM, Heinz Walz, Germany). Os valores de Fv/Fm foram obtidos no pre-dawn e após adaptação ao escuro por 30 minutos (LÜTTGE et al., 1998). O $\Delta \mathrm{F} / \mathrm{Fm}$ ' foi determinado conforme Genty et al. (1989) através 
da fórmula $\Phi=\Delta F / F m^{\prime}=\left(F m^{\prime}-F\right) / F m^{\prime}$, onde $F$ é a fluorescência da clorofila na amostra adaptada à luz e $F m$ ' a máxima fluorescência da amostra à luz, com o pulso saturante. A ETR foi determinada pela fórmula utilizada por RASCHER et al.(2000) ETR = $0,5\left(\Delta F / F m^{\prime}\right) . D F F \cdot 0,84$, onde 0,5 é um fator que considera a excitação luminosa dos dois fotossistemas, $D F F$ corresponde à densidade do fluxo de fótons fotossinteticamente ativos e 0,84 considera que apenas $84 \%$ da irradiância incidente serão absorvidos pela folha.

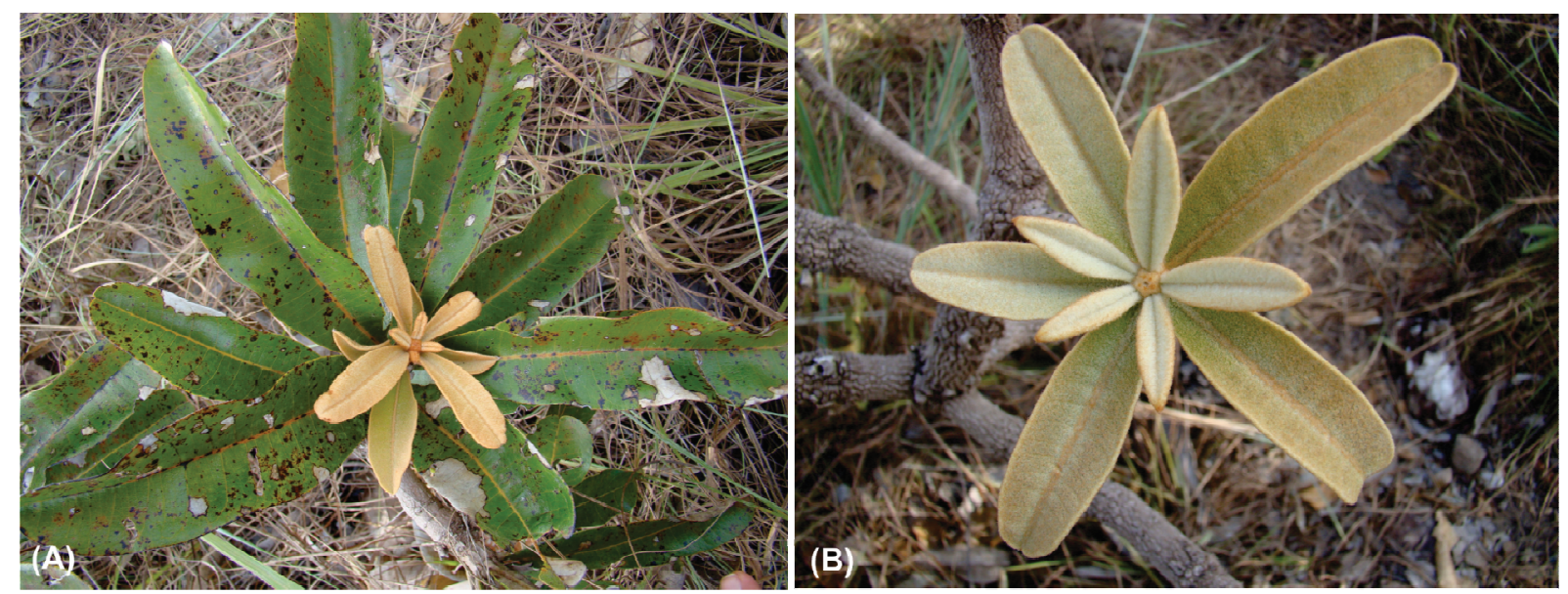

Figura1. Folhas de indivíduos de Vochysia cinnamomea encontrados em área de "cerrado rupestre" da Serra da Canastra, Delfinópolis, MG/Brasil. A) Folhas jovens e maduras de indivíduo de área não queimada. B) Folhas jovens provenientes de brotação pós-queimada.

Nos mesmos indivíduos que foram realizadas as leituras de fluorescência e determinadas as taxas de assimilação líquida de $\mathrm{CO}_{2}$, condutância estomática, transpiração e temperatura foliar, dados obtidos com auxílio do aparelho IRGA (Infra-Red Gas Analyser, LCA-Pro, Analytical Development Co. Ltd., Inglaterra) acoplado a uma câmara foliar PLC4 (B) $\left(6,25 \mathrm{~cm}^{2}\right.$ de área). Foram mensuradas no campo quatro folhas jovens da área queimada, e quatro folhas jovens e maduras da área não queimada, sendo registradas três medidas em cada folha $\mathrm{e}$ as médias consideradas como os valores finais (ao longo do dia, de duas em duas horas). Os registros foram realizados 2 minutos após acoplar as folhas às câmaras para estabilização do equipamento.

Os resultados obtidos entre folhas jovens e maduras de um mesmo indivíduo foram comparados utilizando-se teste $t$ pareado. Os resultados obtidos entre folhas jovens de indivíduos da área queimada e não queimada foram comparados utilizando-se teste $\mathrm{t}$ independente. Quando necessário foram utilizados seus correspondentes não paramétricos (Wilcoxon Ou Mann-Whitney, respectivamente). Para tal utilizou-se o programa SYSTAT (version 10.2.05, 2002). Quando necessário, os dados sofreram transformação logarítmica a fim de se obter normalidade e homocedasticidade (ZAR, 1999). Os dados descritos ao longo do texto representam média \pm desvio padrão.

\section{RESULTADOS}

A temperatura média registrada na área de estudo ao longo do dia em que se realizou a coleta de dados foi de $31,2{ }^{\circ} \mathrm{C}$, sendo a umidade relativa média de $22,8 \%$ e a radiação fotossinteticamente ativa média de $1009,5 \mu \mathrm{mol} \mathrm{m} \mathrm{m}^{-2} \mathrm{~s}^{-1}$. As variações diárias dessas variáveis ambientais estão representadas na Figura2.

Os teores de clorofilas mostraram-se estáveis ao longo do dia nas três condições, não havendo variações relevantes. As folhas maduras apresentaram maiores teores de clorofilas do que as folhas jovens, tanto da área queimada quanto da área não queimada (média de 40,68 \pm 1,41 SPAD para folhas maduras; $29,00 \pm 2,48$ SPAD para folhas jovens de área não queimada e 30,72 $\pm 1,85$ SPAD para folhas jovens de área queimada) (Figura3).

Os valores de rendimento quântico potencial $(\mathrm{Fv} / \mathrm{Fm})$ para as três condições de folhas não diferiram estatisticamente entre si, sendo maiores quando mensurados por volta das 08:00 (Figura4A). Até este horário, os valores permaneceram próximos a 0,8 para os três grupos de folhas analisadas. Ao longo do dia houve ligeira queda desses valores, o que não configurou um quadro de fotoinibição acentuado para $V$. cinnamomea (às 16:00 valores de $\mathrm{Fv} / \mathrm{Fm}$ atingem médias de $0,726 \pm 0,07$ e $0,752 \pm$ 0,05 para folhas jovens da área não queimada $\mathrm{e}$ 
queimada, respectivamente, e $0,722 \pm 0,1$ para

folhas maduras da área não queimada).
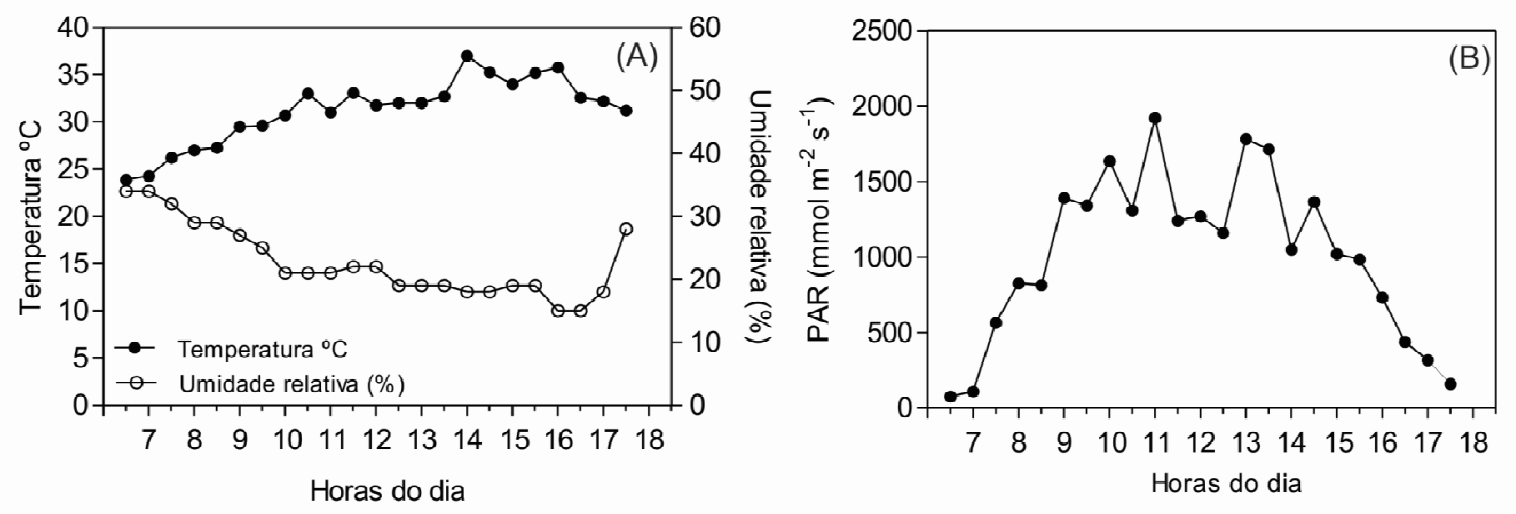

Figura2. Variação diurna da temperatura, umidade relativa do ar (A) e radiação fotossinteticamente ativa (B) em área de "cerrado rupestre" da Serra da Canastra, Delfinópolis, MG/Brasil. Os dados foram coletados em outubro de 2012.

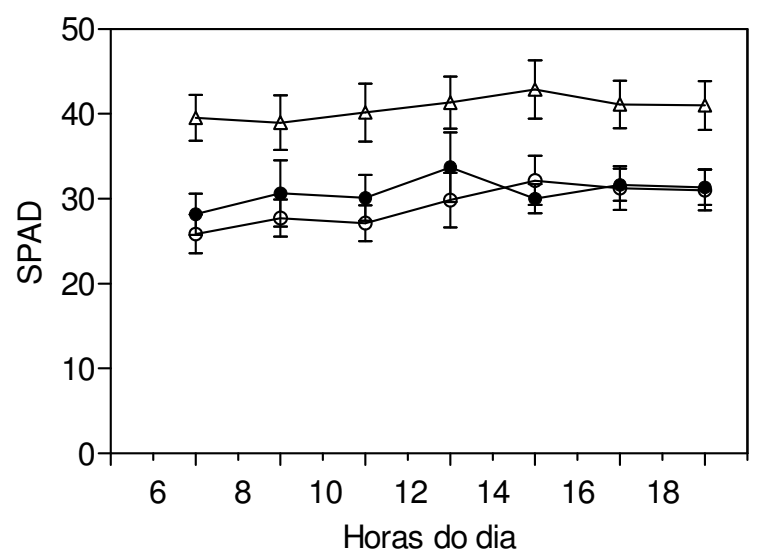

Figura3. Variação dos teores de clorofilas ao longo do dia em folhas jovens (o) e maduras $(\Delta)$ de Vochysia cinnamomea em área não queimada de "cerrado rupestre", e folhas jovens provenientes de brotação pós fogo $(\bullet)$. Os dados (n=6 \pm erro padrão) foram obtidos utilizando-se um clorofilômetro e estão representados em SPAD. A coleta foi realizada em outubro de 2012, Serra da Canastra, Delfinópolis, MG/Brasil.

As curvas diárias do rendimento quântico efetivo $(\Delta \mathrm{F} / \mathrm{Fm}$ ') nas folhas maduras atingiram seu ponto máximo por volta de 12:00 $(0,776 \pm 0,01)$, caindo logo em seguida até cerca de 16:00, quando o rendimento quântico efetivo iniciou sua recuperação e atingiu valores em torno de $0,547 \pm$ 0,17 (Figura4B). Já as folhas jovens (área queimada e não queimada) apresentaram maiores valores de $\Delta \mathrm{F} / \mathrm{Fm}$ ' às 08:00 $(0,669 \pm 0,05$ para folhas jovens da área não queimada e 0,704 $\pm 0,02$ para folhas da área queimada), com queda gradativa até às 16:00. Até esse horário, não se observou recuperação dos fotossistemas das folhas jovens, cujo $\Delta \mathrm{F} / \mathrm{Fm}$ ' apresentou valores baixos, com médias de 0,227 \pm 0,1 e $0,287 \pm 0,1$ para as folhas da área não queimada e queimada, respectivamente. A taxa relativa de transporte de elétrons (ETR - Figura4C) nas folhas maduras e nas folhas jovens da área não queimada atingiram seus maiores valores às 10:00 $\left(200 \pm 16,51\right.$ e $108 \pm 70,64 \mu \mathrm{mol} \mathrm{m} \mathrm{m}^{-2} \mathrm{~s}^{-1}$, respectivamente), enquanto as folhas jovens da área queimada alcançaram esse ponto por volta de 12:00 (aproximadamente $139 \pm 50,43 \mu \mathrm{mol} \mathrm{m} \mathrm{m}^{-2}$ ). Em seguida, as folhas das três condições apresentaram queda gradativa até o fim da tarde. 


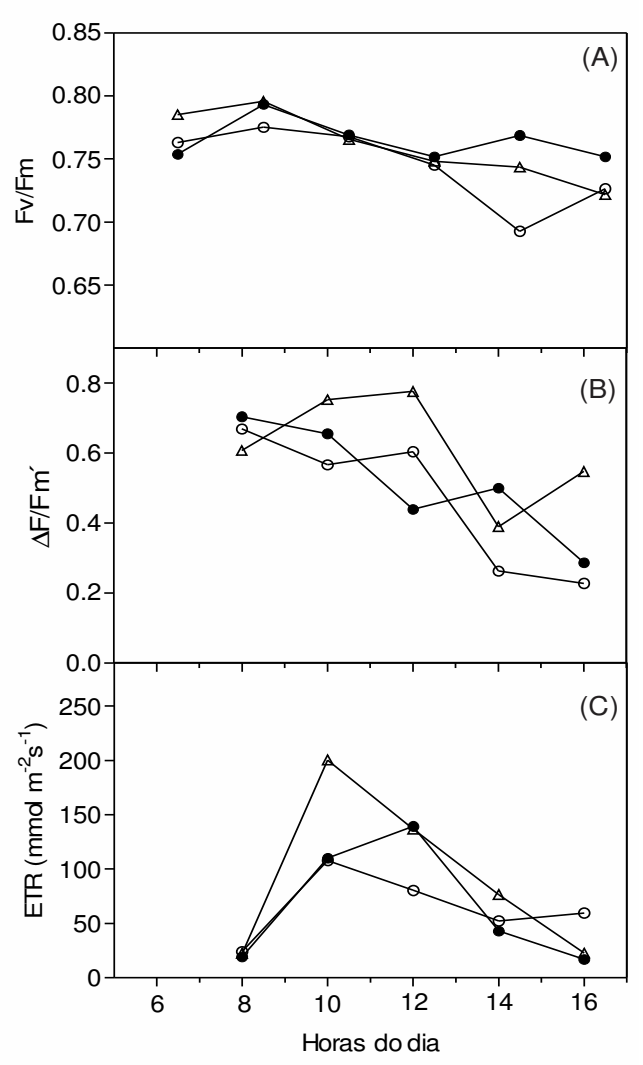

Figura4. A) Rendimento quântico potencial ( $\mathrm{Fv} / \mathrm{Fm})$, (B) rendimento quântico efetivo $(\Delta \mathrm{F} / \mathrm{Fm}$ '), e $(\mathrm{C})$ taxa relativa de transporte de elétrons em folhas jovens $(\circ)$ e maduras $(\Delta)$ de indivíduos de Vochysia cinnamomea encontrados em área não queimada de "cerrado rupestre" e folhas jovens provenientes de brotação pós fogo $(\bullet)$. Os dados (n=6) foram obtidos em outubro de 2012, Serra da Canastra, Delfinópolis, MG/Brasil.

Quanto às respostas relativas às trocas gasosas e temperatura foliar não houve diferença significativa entre as amostras de folhas jovens da área não queimada e queimada para nenhuma das características analisadas (Figura5). Foi observada maior assimilação líquida de $\mathrm{CO}_{2}$ para as folhas maduras quando comparadas com as folhas jovens (Figura5A). Em todas as três condições, a assimilação líquida de $\mathrm{CO}_{2}$ aumentou gradativamente no período da manhã, atingindo por volta das 10:00 valores em torno de 6,18 $\pm 3,94$ $\mu \mathrm{mol} \mathrm{m} \mathrm{m}^{-2}$ nas folhas maduras; $2,82 \pm 4,42 \mu \mathrm{mol}$ $\mathrm{m}^{-2} \mathrm{~s}^{-1}$ nas folhas jovens da área não queimada $\mathrm{e}$ $1,97 \pm 1,84 \mu \mathrm{m}$ nas folhas da área queimada quando iniciou-se leve queda e estabilização dos valores até o fim da tarde. A condutância estomática, transpiração e temperatura foliar foram similares nas três condições analisadas. A transpiração aumentou durante todo o período da manhã, subindo de $1,00 \pm 0,31 \mathrm{mmol} \mathrm{m}^{-2} \mathrm{~s}^{-1}$ às 6:00 para $5,00 \pm 1,32 \mathrm{mmol} \mathrm{m}^{-2} \mathrm{~s}^{-1}$ às 12:00 nas folhas jovens da área queimada e para valores semelhantes às 14:00 nas demais folhas analisadas (Figura5B). Apesar de não serem observadas mudanças bruscas na condutância estomática ao longo do dia, os maiores valores foram observados entre 10:00 e 14:00 tanto para as folhas jovens quanto para as maduras (Figura5C). A temperatura das folhas jovens e maduras, independente de terem estado ou não sob a ação do fogo, atingiu o pico em torno dos $40^{\circ} \mathrm{C}$ por volta das 14:00 (Figura5D), justamente o período mais quente do dia (Figura2A). 

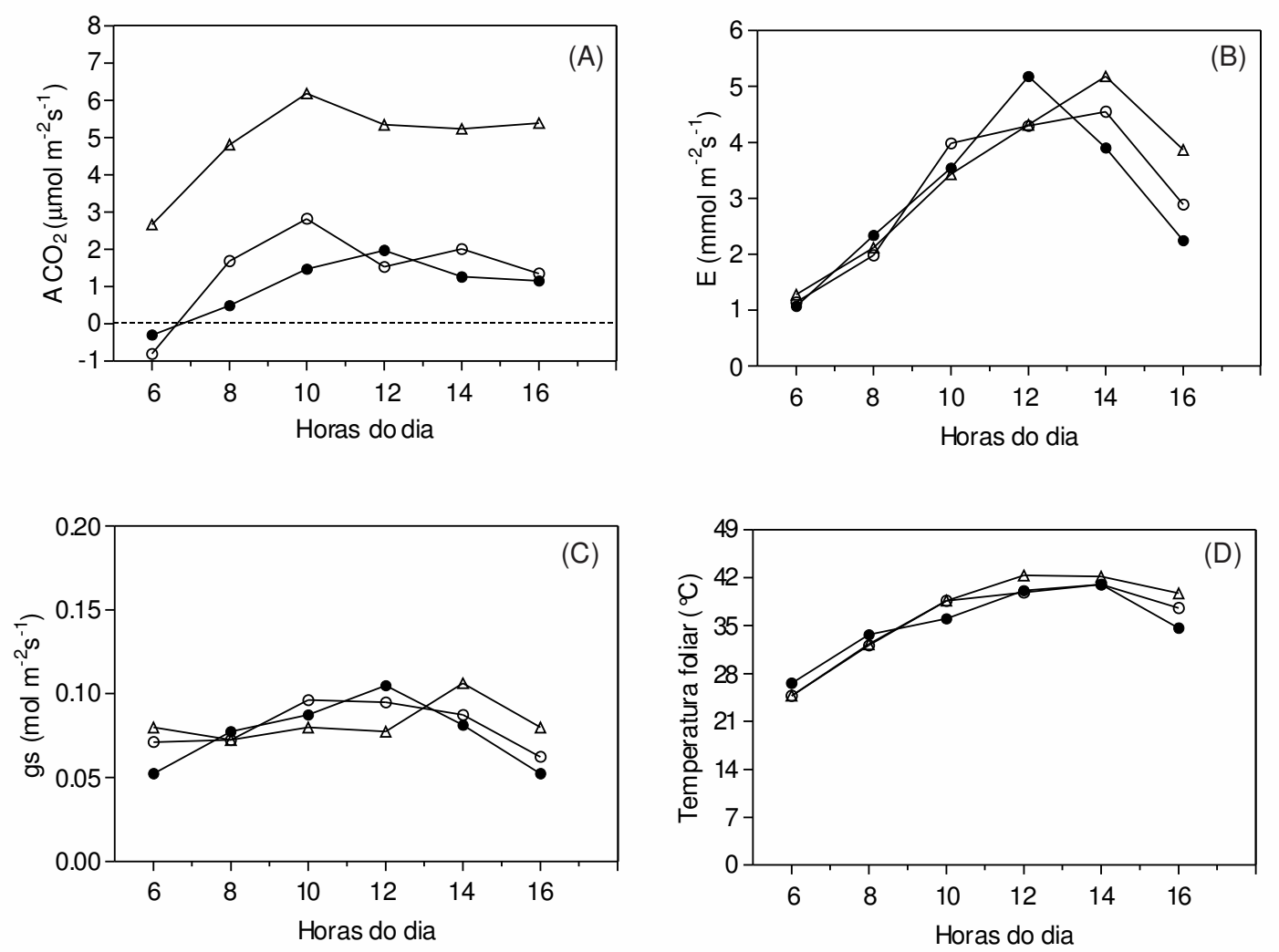

Figura5. A) Assimilação liquida de $\mathrm{CO}_{2}$, (B) transpiração, (C) condutância estomática e (D) temperatura foliar de folhas jovens $(\circ)$ e maduras $(\Delta)$ de indivíduos de Vochysia cinnamomea encontrados em área não queimada de "cerrado rupestre" e folhas jovens provenientes de brotação pós fogo $(\bullet)$. Os dados $(\mathrm{n}=4)$ foram obtidos em outubro de 2012, Serra da Canastra, Delfinópolis, MG/Brasil.

\section{DISCUSSÃO}

As características fisiológicas avaliadas neste estudo mostraram que o fogo não alterou o metabolismo fotossintético de folhas jovens de Vochysia cinnamomea. Entretanto, quando comparadas folhas jovens e maduras, foram observadas diferenças significativas ao longo do dia. As folhas maduras apresentaram ao longo do período de observação teores de clorofilas sempre maiores do que as folhas jovens. Este maior teor de clorofilas nas folhas maduras pode ser explicado pelo fato destas apresentarem aparato fotossintético completamente desenvolvido, enquanto o das jovens ainda está em processo de formação. Maiores teores de clorofila nas plantas aumentam a eficiência de captação de luz na folha (BARROS et al., 2011). Em estudo realizado com folhas jovens de espécies arbóreas tropicais, foi demonstrado que apesar das folhas jovens apresentarem menos de $50 \%$ do teor total de clorofilas do que as folhas maduras, a razão entre clorofilas a/b permanece a mesma (KRAUSE et al., 1995). De acordo com estes autores, pelo fato das folhas jovens serem mais susceptíveis a danos no PSII (susceptibilidade à fotoinibição), maior é o investimento destas na produção de $\alpha$-carotenos e de pigmentos ligados ao ciclo das xantofilas, auxiliando desta forma na manutenção da integridade do aparato fotossintético. Estes pigmentos auxiliares podem ter relação direta com o alto grau de reversibilidade do processo de fotoinibição nestas folhas, o que representa um processo de regulação dinâmico que protege o aparato fotossintético de danos severos decorrentes da alta radiação (KRAUSE et al., 1995). Apesar de Mendes et al. (2001) relatarem degradação da clorofila com o aumento da luminosidade, nossos resultados mostram que nas folhas de $V$. cinnamomea o conteúdo de clorofilas não se altera ao longo do dia.

O rendimento quântico potencial está correlacionado com a eficiência máxima do PSII (MAXWELL; JOHNSON, 2000). É mensurado após a adaptação da planta ao escuro, quando todos os centros de reação estão abertos (os aceptores primários estão oxidados) e a dissipação por calor é mínima. Por ser um sensível indicador do desempenho fotossintético da planta, mudanças em seus valores (diminuição) são resultados da dissipação da energia por calor e por efeitos da 
fotoinibição (MAXWELL; JOHNSON, 2000). Segundo Lüttge et al. (1998), em estudo com espécies do cerrado sensu stricto e campo rupestre, valores inferiores a 0,8 de Fv/Fm já indicam que as plantas se encontram fotoinibidas. Assim, pode-se observar que as folhas maduras e jovens de $V$. cinnamomea já amanhecem levemente fotoinibidas, condição que se acentua com o decorrer do dia. Durante a noite, os centros de reação do PSII se recuperam e um novo ciclo se reinicia. Em espécies de mata, folhas jovens apresentam maior susceptibilidade à fotoinibição (KRAUSE et al., 1995), fato não observado em $V$. cinnamomea, encontrada em área de cerrado rupestre.

O desempenho fotossintético real da planta pode ser representado pelo rendimento quântico efetivo, indicando a proporção de luz absorvida pela clorofila associada ao PSII que é usada na fase fotoquímica da fotossíntese. Vochysia cinnamomea consegue aumentar a eficiência quântica de suas folhas maduras juntamente com o aumento da radiação no período da manhã. Entretanto, a alta radiação e a baixa umidade relativa do ar a partir das 12:00 parecem ter efeito decisivo no funcionamento do PSII. Neste momento, a queda dos valores de $\Delta \mathrm{F} / \mathrm{Fm}$ ' nas folhas maduras faz que estes alcancem níveis similares aos das folhas jovens (independente da ação do fogo), que demonstraram redução gradativa da eficiência quântica desde as 8:00 da manhã.

Lemos-Filho (2000), em estudo com espécies de Cerrado (Annona crassifolia, Eugenia dysenterica e Campomanesia adamantium) obtiveram valores máximos de taxas relativas de transporte de elétrons (ETR) em torno de $200 \mu \mathrm{mol}$ $\mathrm{m}^{-2} \mathrm{~s}^{-1}$ na estação chuvosa e $100 \mu \mathrm{mol} \mathrm{m} \mathrm{m}^{-2} \mathrm{~s}^{-1}$ na estação seca. Em nosso estudo, as folhas maduras também alcançaram valores de ETR próximos a 200 $\mu \mathrm{mol} \mathrm{m} \mathrm{m}^{-2} \mathrm{~s}^{-1}$ E É comum que plantas crescidas a pleno sol, como é o caso dos indivíduos deste trabalho, apresentem altas taxas de ETR. Comparativamente, em áreas de Cerrado e Floresta Atlântica, Barros et al. (2011) constataram que indivíduos adultos de Dalbergia sp. sob o sol apresentaram valores mais elevados de ETR do que indivíduos crescidos na sombra, com valores máximos em torno de 62 e 36 $\mu \mathrm{mol} \mathrm{m}^{-2} \mathrm{~s}^{-1}$ para o pleno sol e sombra, respectivamente.

A transição entre o fim da estação seca e o início da estação chuvosa na área de estudo caracteriza-se por temperaturas elevadas e PAR intensa ao longo do dia. Sob essas condições, as taxas fotossintéticas tendem a cair, o que resulta em menores índices gerais de assimilação líquida de $\mathrm{CO}_{2}$ e de condutância estomática (HOLBROOK et al., 1995). A assimilação de $\mathrm{CO}_{2}$ crescente nas primeiras horas do dia, tanto nas folhas maduras quanto nas folhas jovens, coincide com o aumento da condutância estomática, transpiração e PAR. Entretanto, apesar da assimilação apresentar uma queda a partir das 10:30, a condutância e a transpiração apenas mostram redução depois do meio dia. Tal fato pode ser associado às altas temperaturas (às 10:30 a temperatura foliar alcança valores superiores a $35^{\circ} \mathrm{C}$ ), que, por sua vez, aumentam a taxa de fotorrespiração em plantas com metabolismo $\mathrm{C}_{3}$, fato decorrente do desequilíbrio na atividade carboxilase/oxidase da rubisco, o que pode auxiliar na dissipação de calor, porém reduz a eficiência na fixação de $\mathrm{CO}_{2}(\mathrm{KU}$; EDWARDS, 1977). De acordo com Franco et al. (2007), espécies que apresentam redução na taxa de assimilação de carbono, comumente podem manter altas taxas de ETR na cadeia fotoquímica (100 a $400 \mu \mathrm{mol} \mathrm{m}^{-2} \mathrm{~s}^{-}$ ${ }^{1}$ ), sendo o excesso energético dissipado pela fotorrespiração e por ajustes no ciclo dos carotenoides.

Angelopoulos et al. (1996) correlacionaram o aumento do grau de estresse com a queda expressiva da capacidade de transporte de elétrons. Assim, em nosso estudo a queda de ETR, principalmente após as 10:00, indica um aparato fotossintético sob estresse. As folhas nas duas fases de desenvolvimento de $V$. cinnamomea aqui estudadas apresentaram queda na assimilação líquida de $\mathrm{CO}_{2}$, principalmente após as 10:30, e essa queda é acompanhada pelo decréscimo também da ETR. Assim, os resultados do presente estudo mostram que em $V$. cinnamomea a queda na assimilação de $\mathrm{CO}_{2}$ não ocorre somente pelo aumento na fotorrespiração, mas também pode ser afetada pela menor eficiência quântica. $\mathrm{O}$ aumento gradativo na condutância estomática nos horários com maior temperatura e menor umidade relativa do ar (ver Figuras5c e 1a), indica que o suprimento de $\mathrm{CO}_{2}$ é mantido e sugere que este não é fator limitante no ciclo de Calvin.

Pode-se supor que as folhas jovens tenderiam a sofrer maior aumento de temperatura por não apresentarem estado de maturação fisiológico plenamente desenvolvido para lidar com a elevação dessa variável ambiental e com a alta incidência de energia luminosa. No entanto, características morfológicas, como maior densidade de tricomas - que exercem um papel refletor da irradiância excessiva - observada nas folhas jovens e maior suculência estariam compensando essas ineficiências e auxiliando no controle da temperatura e na diminuição da ação do vento, 
conforme proposto por Woodnam e Fernandes (1991) para outras espécies do Cerrado.

Deve-se considerar que neste trabalho as únicas variações significativas foram encontradas não entre indivíduos de áreas queimadas e não queimadas, mas comparando-se folhas jovens e maduras. É fato que estas folhas são estruturalmente distintas (folhas jovens mais suculentas e pilosas e folhas maduras mais coriáceas, glabras e com cutícula evidente) e encontram-se em estágios fisiológicos de maturação também distintos, indicados principalmente pelas diferenças no conteúdo de pigmentos cloroplastídicos e na assimilação líquida de $\mathrm{CO}_{2}$. Alguns estudos, como de Knapp (1985), apontam que fatores como assimilação líquida de $\mathrm{CO}_{2}$, condutância estomática e fotossíntese de um modo geral tendem a aumentar em resposta a queimadas. $\mathrm{O}$ efeito do fogo como modelador da paisagem e condutor da dinâmica vegetal é certo (KEELEY et al., 2012; HE et al., 2012). Porém, neste estudo se conclui que o fogo não exerceu influência direta sobre os processos fisiológicos de $V$. cinnamomea, espécie nativa do Cerrado.

\section{AGRADECIMENTOS}

À Ana Laura T. Costa e à Isabella C. Cardoso pelo auxílio em campo com a coleta de dados. Ao CNPq (PELD - 403733/2012-0) e à FAPEMIG (CRA-656-11, PACCSS/CRA30058/12) pelo auxílio financeiro.

\begin{abstract}
Post-fire effect plays an important role as a modulator of plant ecosystems, especially of the Cerrado. It induces leaf sprouting in several species, often forming vigorous and more physiologically active leaves. In the present study it was investigated the photosynthetic performance of young and mature leaves of Vochysia cinnamomea Pohl (Vochysiaceae) in response to the fire action in a "cerrado rupestre" area of Serra da Canasta, Minas Gerais, comparing; (1) young leaves from fired and intact area, and (2) young and mature leaves from the same plant. Mature leaves from intact area plants which leaf sprouting occurred before fire action in the adjacent area, and young leaves from intact and fired area which leaf sprouting occurred after fire action were analyzed. Data were collected and analyzed on photosynthetic rates, potential and effective quantum yield, electron transport rate, $\mathrm{CO}_{2}$ assimilation, stomatal conductance, transpiration and chlorophyll contents. There were no significant differences between the young leaves of the burned and unburned area in relation to physiological parameters tested. Thus there is no kind of quick response in relation to fire effects. However, significant differences between young and mature leaves were found. Young leaves are structurally distinct of the mature leaves, been more succulent and pilous while mature leaves are more coriaceous, glabrous and with thicked cuticle. The structural differences between young and mature leaves are reflected in distinct physiological performance. Mature leaves present lower degree of photoinhibition, higher pigment content and $\mathrm{CO}_{2}$ assimilation.
\end{abstract}

KEYWORDS: Chlorophyll. Photoinhibition. Quantum yield. Electron transport rate. Gas exchanges.

\title{
REFERÊNCIAS
}

ANGELOPOULOS, K.; DICHIO, B.; XILOYANNIS, C. Inhibition of photosynthesis in olive trees (Olea europaea L.) during water stress and rewatering. Journal of Experimental Botany, Lancaster, v. 47, n. 8, p. 1093-1100, ago.1996.

ARIEIRA, J.; CUNHA, C. N. Fitossociologia de uma floresta inundável monodominante de Vochysia divergens Pohl (Vochysiaceae), no Pantanal Norte, MT, Brasil. Acta Botanica Brasilica, Belo Horizonte, v. 20, n. 3, p. 569-580, mai. 2006.

BARROS, F. V.; GOULART, M. F.; SÁ TELLES, S. B.; LOVATO, M. B.; VALLADARES, F.; LEMOSFILHO, J. P. Phenotypic plasticity to light of two congeneric trees from contrasting habitats: Brazilian Atlantic Forest versus cerrado (savanna). Plant Biology, Chichest, v. 14, p. 208-215, mai. 2011.

COUTINHO, L. M. Aspectos ecológicos do fogo no Cerrado. II- As queimadas e a dispersão de sementes de algumas espécies anemocóricas do estrato herbáceo-subarbustivo. Boletim de Botânica, São Paulo, v. 5, p. 5764, 1977. http://dx.doi.org/10.11606/issn.2316-9052.v5i0p57-63 
FRANÇA, F. Vochysiaceae in Lista de Espécies da Flora do Brasil, Jardim Botânico do Rio de Janeiro, 2015a. Disponível em: <http://floradobrasil.jbrj.gov.br/jabot/floradobrasil/FB250>. Acesso em: $04 \mathrm{de}$ fevereiro de 2015.

FRANÇA, F. Vochysiaceae in Lista de Espécies da Flora do Brasil, Jardim Botânico do Rio de Janeiro, 2015b. Disponível em: <http://floradobrasil.jbrj.gov.br/jabot/floradobrasil/FB15300>. Acesso em: 04 de fevereiro de 2015.

FRANCO, A.C.; MATSUBARA, S.; ORTHEN, B. Photoinhibition, carotenoid composition and the coregulation of photochemical and non-photochemical quenching in neotropical savanna trees. Tree Physiology, Oxford, v. 27, p. 717-725, mai. 2007.

FURLEY, P. A. The nature and diversity of neotropical savanna vegetation with particular reference to the Brazilian cerrados. Global Ecology and Biogeography, Weinheim, v. 8, p. 223-241, dez. 2002. http://dx.doi.org/10.1046/j.1466-822X.1999.00142.x http://dx.doi.org/10.1046/j.1365-2699.1999.00142.x

GENTY, B.; BRIANTAIS, J. M.; BAKER, N. The relationship between quantum yield of photosynthetic electron transport and quenching of chlorophyll fluorescence. Biochimica Biophysica Acta, Nijmegen, v. 990, p. 87-92, jan. 1989. http://dx.doi.org/10.1016/S0304-4165(89)80016-9

GOTTSBERGER, G.; SILBERBAUER-GOTTSBERGER, I. Life in the Cerrado: a South American Tropical Seasonal Vegetation. Ulm: Universität Ulm, Systematische Botanik und Ökologie und Botanischer Garten, 2006. Vol. I. Origin, Structure, Dynamics and Plant Use.

HE, T.; PAUSAS, J. G.; BELCHER, C. M.; SCHWILK, D. W.; LAMONT, B. B. Fire-adapted traits of Pinus arose in the fiery Cretaceous. New Phytologist, Lancaster, v. 194, p. 751-759, mai. 2012.

HOLBROOK, M. N.; WHITBECK, J. L.; MOONEY, H. A. Drought responses of neotropical dry forest trees. In: BULLOCK, S. H.; MOONEY, H. A.; MEDINA, E. (eds). Seasonally dry tropical forests. Cambridge: Cambridge University Press, 1995, p. 243-270. http://dx.doi.org/10.1017/CBO9780511753398.010

KEELEY, J. E.; BOND, W. J.; BRADSTOCK, R. A.; PAUSAS, J. G.; RUNDEL, P. W. Fire in Mediterranean ecosystems: ecology, evolution and management. Cambridge: Cambridge University Press, 2012. $515 \mathrm{p}$.

KNAPP, A. K. Effect of fire and drought on the ecophysiology of Andropogon gerardii and Panicum virgatum in a tallgrass prairie. Ecology, New York, v. 66, n. 4, p. 1309-1320, ago. 1985.

KOTTEK, M.; GRIESER, J.; BECK, C.; RUDOLF, B.; RUBEL, F. World Map of the Köppen-Geiger climate classification updated. Meteorologische Zeitschrift, v. 15, n. 3, p. 259-263, jun. 2006.

http://dx.doi.org/10.1127/0941-2948/2006/0130

KRAUSE, G. H.; VIRGO, A.; WINTER, K. High susceptibility to photoinhibition of young leaves of tropical forest trees. Planta, Heidelberg, v. 197, n. 4, p. 583-591, 1995.

KU, S. B.; EDWARDS, G. E. Oxygen inhibition of photosynthesis. Plant Physiology, v. 59, p. 991-999, mai. 1977.

LEMOS-FILHO, J. P. Fotoinibição em três espécies do cerrado (Annona crassifolia, Eugenia dysenterica e Campomanesia adamantium) na estação seca e na chuvosa. Revista Brasileira de Botanica, São Paulo, v. 23, n. 1, p. 45-50, mar. 2000.

LÜTTGE, U.; HARIDASAN, M.; FERNANDES, G. W.; MATTOS, E. A.; TRIMBORN, P.; FRANCO, A. C.; CALDAS, L. S.; ZIEGLER, H. Photosynthesis of mistletoes in relation to their hosts at various sites in tropical Brazil. Trees, Darmftadt, v. 12, p. 167-174, jan. 1998. 
MAGALHÃES, S. R.; LIMA, G. S.; RIBEIRO, G. A. Avaliação dos incêndios florestais ocorridos no Parque Nacional da Serra da Canastra - Minas Gerais. Cerne, Lavras, v. 18, n. 1, p. 135-141, jan./mar. 2012.

MAXWELL, K.; JOHNSON, G. N. Chlorophyll fluorescence - a practical guide. Journal of Experimental Botany, Oxford, v. 51, n. 345, p. 659-668, abr. 2000. http://dx.doi.org/10.1093/jexbot/51.345.659

MEDEIROS, M. B.; FIEDLER, N. C. Incêndios florestais no Parque Nacional da Serra da Canastra: desafios para a conservação da biodiversidade. Ciência Florestal, Santa Maria, v. 14, n. 2, p. 157-168, dez. 2004.

MENDES, M. M.; GAZARINI, L. C.; RODRIGUES, M. L. Acclimation of Myrtus communis to contrasting Mediterranean light environments - effects on structure and chemical composition of foliage and plant water relations. Environmental and Experimental Botany, Paris, v. 45, p. 165-178, abr. 2001.

http://dx.doi.org/10.1016/S0098-8472(01)00073-9

RASCHER, U.; LIEBIG, M.; LÜTTGE, U. Evaluation of instant light-response curves of chlorophyllfluorescence parameters obtained with a portable chlorophyll fluorometer on site in the field. Plant, Cell and Environment, Washington, v. 23, p. 1397-1405, dez. 2000. http://dx.doi.org/10.1046/j.13653040.2000.00650.x

WOODNAM, R. L.; FERNANDES, G. W. Differential mechanical defense: herbivory, evapotranspiration and leaf-hairs. Oikos, Copenhagen, v. 60, p. 11-19, abr. 1991. http://dx.doi.org/10.2307/3544986

ZAR, J. H. Biostatistical Analysis. 4 ed. New Jersey: Prentice Hall Inc., Upper Saddle River, 1999. 662p. 